\title{
PENGARUH LATIHAN PENCAK SILAT MENGGUNAKAN BEBAN DEMPEL TERHADAP KECEPATAN TENDANGAN DEPAN PESILAT DI PADEPOKAN PSHT CABANG LAMPUNG BARAT
}

\author{
Lungit Wicaksono ${ }^{1}$, Totok Sardianto ${ }^{2}$, Dimas Duta Putra Utama ${ }^{3}$ \\ 1,2,3 Program Studi Penjaskes Universitas Lampung \\ E-mail: lungit.wicaksono02@fkip.unila.ac.id', totok.sardianto28@gmail.com², \\ dimasutama33139@gmail.com ${ }^{3}$ \\ DOI: https://doi.org/10.36526/kejaora.v5i2.958
}

\begin{abstract}
ABSTRAK
Masalah dalam penelitian ini adalah kurangnya kecepatan dalam melakukan tendangan depan. Penelitian ini bertujuan untuk mengetahui pengaruh dengan memberikan suatu perlakuan yaitu latihan menggunakan beban . Jenis penelitian yang digunakan adalah metode eksperimen dengan sampel sebanyak 40 orang. Teknik pengumpulan data menggunakan instrumen kecepatan tendangan depan, Berdasarkan hasil penelitian dan hasil dari uji normalitas, uji homogenitas dan uji hipotesis yang diperoleh dari kelompok eksperimen yaitu ada pengaruh dari latihan beban dampel terhadap kecepatan tendangan dengan nilai $r_{\text {hitung }} 0,8938>r_{\text {tabel }} 0,444$ dengan $\alpha=0,05$. Kelompok kontrol $r_{\text {hitung }} 0,9072>r_{\text {tabel }}$ 0,444. Dengan thitung 39,74 $>t_{\text {tabel }} 2,038$ distribusi dari hasil tersebut terdapat perbedaan yang signifikan antara kelompok eksperimen dan kelompok kontrol. Perhitungan uji analisis kelompok kontrol dan kelompok eksperimen menunjukkan bahwa kelompok eksperimen dengan latihan menggunakan beban dempel berpengaruh lebih baik terhadap kecepatan tendangan depan pesilat di Padepokan PSHT Cabang Lampung Barat.
\end{abstract}

Kata Kunci: Pencak Silat, Beban Dempel, Kecepatan Tendangan Depan

\section{PENDAHULUAN}

Pencak Silat adalah suatu cara beladiri yang menggunakan akal sepenuhnya. Akal yang dimiliki manusia lebih sempurna bila dibandingkan dengan makhluk-makhluk yang lain nya. Oleh karena itu, tidak mustahil jika manusia dapat menguasai segala macam ilmu di dunia ini (Koesopangat 2012). Sedangkan Menurut Maryono (2010) pencak silat adalah gerakan langkah keindahan dengan menghindar yang disertakan gerakan berunsur komedi. Pencak dapat dipertontonkan sebagai sarana hiburan, pernyataan senada diperkuat oleh Wongsonegoro (2011) Ketua IPSI yang pertama mengatakan bahwa pencak adalah gerakan serang bela yang berupa tari dan berirama dengan pengaturan ada kesopanan tertentu yang biasa dipertunjukan di depan umum. sedangkan Silat adalah unsur teknik beladiri menangkis, menyerang, dan mengunci yang tidak dapat diperagakan di depan umum.
Di Indonesia terdapat banyak aliranaliran silat dan adanya event-event tahunan mulai dari tingkat pedesasan sampai jenjang internasional latihan-latihan untuk menuju prestasi harus dilakukan sedini mungkin. Seperti halnya olahraga bela diri yang lain pencak silat juga ditentukan oleh kekuatan, kecepatan, kelincahaan, daya tahan dan keseimbangan. Jadi, dari beberapa faktor diatas yang mempengaruhi keterampilan dalam melakukan tendangan maka dari itu dalam olahraga Pencak Silat haruslah memiliki tendangan yang kuat dan cepat. Bagi seorang pesilat kurangnya kecepatan serta kekuatan power tendangan menjadi kendala yang sering terjadi dalam olahraga Pencak Silat.

Dalam olahraga Pencak Silat kecepatan sangat dibutuhkan karena dengan kecepatan gerak yang tinggi akan sulit diduga oleh lawan kemana tangan dan kaki akan bergerak, atau dengan kecepatan yang tinggi lawan akan terlambat untuk melakukan 
Jurnal Kejaora: Jurnal Kesehatan Jasmani dan Olah Raga

ISSN: 2541-5042 (Online)

ISSN: 2503-2976 (Print)

Volume 5 Nomor 2, Edisi November 2020

tangkisan. (Wardoyo 2014) gerak dasar pencak silat adalah suatu gerak terencana, terarah, terkoordinasi dan terkendali, yang mempunyai empat aspek sebagi satu kesatuan, yaitu aspek mental spiritual, aspek beladiri, aspek olahraga, dan aspek seni budaya Sedangkan menurut Irianto (2011) teknik adalah suatu proses gerakan dan pembuktian dalam praktek dengan sebaik mungkin untuk menyelesaikan tugas yang pasti dalam cabang olahraga sesui dengan pendapat yang di kemukakan oleh pelatih pencak silat Indonesia Lubis (2010) mengatakan bahwa teknik dasar yang harus dimiliki oleh calon atlet pencak silat adalah kecepatan tendangan. Menurut Novitasari (2017) menyatakan bahwa:"Kecepatan tendangan dapat ditingkatkan menggunakan latihan beban yaitu dengan menggunakan beban dempel. Dempel yang bersifatnya berat merupakan alat bantu latihan yang dapat digunakan untuk meningkatkan kecepatan tendangan. Sedangkan menurut Pranata (2017). Menyatakan bahwa "Latihan tahanan tersebut harus dilakukan sedemikian rupa sehingga atlet harus mengeluarkan tenaga maksimal atau hampir maksimal untuk menahan beban. Beban tersebut sedikit demi sedikit bertambah volumenya agar perkembangan otot terjamin.

Arti modifikasi secara umum adalah mengubah atau menyesuaikan, sedangkan menurut beberapa ahli, mengemukakan bahwa modifikasi dapat diartikan sebagai upaya melakukan perubahan dengan penyesuaian-penyesuaian baik segi fisik material (fasilitas dan perlengkapan) maupun dalam tujuan dan cara (metode, gaya, pendekatan, aturan serta penilaian) (Bahagia 2010). Modifikasi disini mengacu pada sebuah penciptaan, penyesuaian dan menampilkan suatu alat/sarana dan prasarana yang baru, unik, dan menarik. Istilah latihan beban sebagaimana dipergunakan disini adalah meliputi penggunaan dempel. Sedangkan Harsono (2010) menyatakan latihan yang sistematis dimana beban hanya dipakai sebagai alat untuk menambahkan kekuatan otot guna mencapai tujuan tertentu misal memperbaiki kondisi fisik, kesehatan, kekuatan, prestasi dalam cabang olahraga dan sebagainya, Dari

pengertian diatas maka peneliti memilih ban sebagai beban yang digunakan sebagai beban latihan, dan bentuk modifikasi adalah berupa Ban dalam sepeda motor yang masing masing diisi dengan pasir dan berjumlah 1 buah, kemudian beban ini diikatkan ke salah satu kaki terkuat calon atlet yang akan melakukan tendangan.

Oleh karena itu calon atlet atlet perlu melakukan latihan menggunakan beban agar kemampuan tendangannya dapat ditingkatkan. Untuk meningkatkan kemampuan tendangan seorang calon atlet ketika latihan dapat melakukan metode latihan dengan menambahkan pemberat di pergelangan kakinya untuk meningkatkan kemampuan tendangannya sehingga tidak mudah lagi ditangkap oleh lawan. Latihan beban disarankan karena banyaknya beban dapat diatur sedemikian rupa sehingga makin lama makin bertambah. Latihan beban pada umumnya dapat dimodifikasi dengan mudah, disini peneliti menggunakan beban dempel modifikasi yaitu menggunakan ban dalam sepeda motor yang diisi oleh pasir dengan berat $1,5 \mathrm{~kg}$ putra dan $1 \mathrm{~kg}$ putri Ini sangat disarankan karena lebih aman dari pada menggunakan beban barbel.

\section{METODE}

Metode penelitian dalam penelitian ini adalah menggunakan metode eksperimen. Menurut Arikunto (2010) penelitian eksperimen adalah Suatu cara untuk mencari hubungan sebab akibat antara dua faktor yang sengaja ditimbulkan oleh peneliti dengan mengeleminasi atau mengurangi faktor lain yang mengganggu eksperimen dilakukan untuk melihat akibat suatu perlakuan. Rancangan desain penelitian dapat digambar seperti berikut :

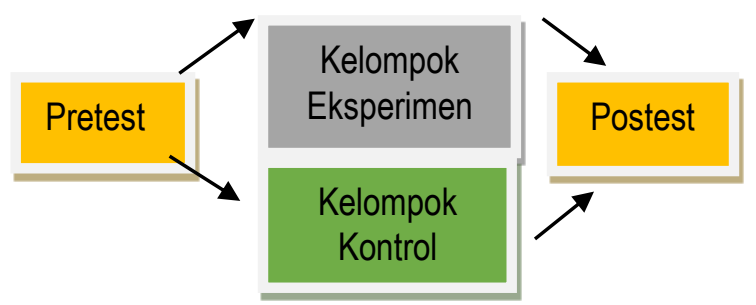

Gambar 1. Desain Penelitian 
Jurnal Kejaora: Jurnal Kesehatan Jasmani dan Olah Raga

ISSN: 2541-5042 (Online)

ISSN: 2503-2976 (Print)

Volume 5 Nomor 2, Edisi November 2020

Dalam penelitian ini instrumen yang digunakan yaitu menggunakan kemampuan kecepatan tendangan depan pada box target. Kemudian untuk pengambilan data preetest setiap calon atlet kelompok eksperimen maupun kelompok kontrol bersiap-siap dibelakang sansack/target dengan satu kaki tumpu berada di belakang garis sejauh $50 \mathrm{~cm}$ untuk putri dan $60 \mathrm{~cm}$ untuk putra. Pada saat aba-aba ya/peluit calon atlet melakukan tendangan dengan kaki kanan dan kembali keposisi awal dengan menyentuh lantai yang berada dibelakang garis kemudian melanjutkan tendangan kanan secepat cepatnya dan sebanyak - banyaknya selama 10 detik. Pelakasanan dilakukan tiga kali dan waktu yang terbaik dengan ketingggian sandsack $75 \mathrm{~cm}$ putri dan $100 \mathrm{~cm}$ putra, waktu terbaik itu yang akan dijadikan sebagai data pree test. Dan untuk proses latihan dilakukan selama 14 Pertemuan diluar pree test dan post test dengan seminggu 3 kali pertemuan, selama 14 pertemuan tersebut kelompok eksperimen melakukan latihan tendangan dengan salah satu kaki terkuat dikaitkan dengan beban dempel dengan menggunakan program latihan sebagai berikut :

Tabel 1. Program Latihan

\begin{tabular}{cccc}
\hline Minggu & $\begin{array}{c}\text { Irama } \\
\text { lathan }\end{array}$ & $\begin{array}{c}\text { Repetisi } \\
2-5 \text { kali }\end{array}$ & $\begin{array}{c}\text { Set 1-4 } \\
\text { kali }\end{array}$ \\
\hline I & Lambat & 2 & 1 \\
\hline II & Sedang & 2 & 2 \\
\hline III & Cepat & 2 & 2 \\
\hline IV & Cepat & 4 & 3 \\
\hline V & Cepat & 4 & 3 \\
\hline
\end{tabular}

Sumber: Peneliti

Sedangkan kelompok kontrol melakukan latihan tanpa menngunakan beban dan juga tanpa program latihan yang diberikan pelatih, setelah kelompok eksperimen dan kelompok kontrol melakukan latihan selama 14 pertemuan selanjutnya dilakukan pengambilan data post test untuk mengetahui ada tidaknya pengaruh latihan menggunakan beban dempel terhadap kecepatan tendangan depan, dengan teknis pengambilan sama dengan pengambilan data awal.

Tabel 2. Penilaian Hasil Kecepatan Tendangan Depan Pencak Silat.

\begin{tabular}{ccc}
\hline Kategori & Putri (detik) & Putra (detik) \\
\hline Baik Sekali & $>28$ & $>30$ \\
\hline Baik & $23-27$ & $25-29$ \\
\hline Cukup & $18-22$ & $19-24$ \\
\hline Kurang & $14-17$ & $15-18$ \\
\hline Kurang Sekali & $<13$ & $<14$ \\
\hline Sumber: Peneliti & &
\end{tabular}

Teknik analisis data dalam penelitian ini menggunakan uji normalitas untuk mengetahui data yang berasal dari kedua kelas berupa nilai hasil belajar berasal dari polulasi yang berdistribusi normal atau tidak. Penelitian ini menggunakan uji normalitas data menggunakan rumus Chi-kuadrat $\left(\mathrm{X}^{2}\right)$ (Sugiono 2015). Uji homogenitas dilakukan untuk mengetahui data memiliki varians yang sama (homogen) atau tidak. Penelitian ini menggunakan uji homogenitas dilakukan ujiF (Sudjana 2015). Sedangkan pengujian hipotesis dilakukan untuk memperoleh kesimpulan apakah nantinya hipotesis yang kita ajukan diterima atau ditolak. Adapun uji yang peneliti gunakan untuk menguji hipotesis adalah uji regresi linier sederhana dan uji-t. Uji regresi linier sederhana digunakan untuk mengetahui ada tidaknya.

\section{HASIL DAN PEMBAHASAN}

Hasil dari perhitungan uji normalitas data dapat dilihat pada tabel berikut:

Tabel 3. Hasil Data Normalitas

\begin{tabular}{llll}
\hline Data Kelas & $X_{\text {Hitung }}$ & $X_{\text {Hitung }}$ & Keputusan \\
\hline $\begin{array}{l}\text { Pretest } \\
\text { eksperimen }\end{array}$ & 6,7954 & 9,4877 & Normal \\
dan kontrol & & & \\
\hline $\begin{array}{l}\text { Postest } \\
\text { eksperimen } \\
\text { dan kontrol }\end{array}$ & 7,2744 & 9,4877 & Normal \\
$\begin{array}{l}\text { Sumber: Peneliti } \\
\text { Sum }\end{array}$ & & \\
\end{tabular}

Berdasarkan hasil uji normalitas pada tabel diatas, dapat diketahui bahwa hasil posttest kelas eksperimen dan kontrol berdistribusi normal untuk $\alpha=0,05$ dengan $\mathrm{dk}=\mathrm{k}-1=5-1=4$, maka dicari pada tabel chikuadrat $X_{\text {tabel }}^{2} 9,4877$. Sehingga diperoleh $X_{\text {hitung }}^{2} 7,2744 \leq 9,4877$. Berarti data hasil 
Jurnal Kejaora: Jurnal Kesehatan Jasmani dan Olah Raga

ISSN: 2541-5042 (Online)

ISSN: 2503-2976 (Print)

Volume 5 Nomor 2, Edisi November 2020

post-test kelas eksperimen dan kelas kontrol berdistribusi normal.

Tabel 4. Hasil Data Homogenitas

\begin{tabular}{lccc}
\hline Data Kelas & FHitung & FHitung & Keputusan \\
\hline $\begin{array}{l}\text { Pretest } \\
\text { eksperimen } \\
\text { dan kontrol }\end{array}$ & 1,04 & 2,15 & Homogen \\
\hline $\begin{array}{l}\text { Postest } \\
\text { eksperimen } \\
\text { dan kontrol }\end{array}$ & 1,08 & 2,15 & Homogen \\
$\begin{array}{l}\text { Sumber: Peneliti } \\
\text { Sumbron }\end{array}$ & & \\
\end{tabular}

Hasil posttest peserta didik diperoleh $F_{\text {hitung yaitu }} 1,08$ sedangkan $F_{\text {tabel }}$ dengan taraf signifikan 00,5 Berdasarkan dua dk tersebut, maka dapat diketahui bahwa harga $\mathrm{F}$ tabel untuk $a=0,05=2,15$. Ternyata harga $F$ hitung $1,08<F$ tabel 2,15, maka hal ini berarti data bersifat homogen.

Tabel 5. Hasil Uji regresi linear sederhana kelompok eksperimen

\begin{tabular}{ccccc}
\hline Variabel & $\mathrm{N}$ & RHHitung & RTabel $_{\text {Kesimpulan }}$ \\
\hline$X-Y$ & 20 & 0,9072 & 0,444 & Signifkan \\
\hline \multicolumn{2}{l}{ Sumber: Peneliti } & & &
\end{tabular}

Di peroleh $r_{\text {hitung }} 0,9072$ dengan $\mathrm{N}=$ 20 untuk $a=0,05$, maka $r_{\text {tabel }} \quad 0,3610$; sehingga

$r_{\text {hitung }} 0,9072>r_{\text {tabel }} 0,444$. Berdasarkan

perhitungan regresi linear sederhana dapat disimpulkan bahwa ada pengaruh tretment beban dempel terhadap kecepatan tendangan depan pesilat di Padepokan PSHT Cabang Lampung Barat.

Tabel 6. Hasil Uji regresi linear sederhana kelompok kontrol

\begin{tabular}{lllll}
\hline Variabel & $\mathrm{N}$ & RHitung & $\mathrm{R}_{\text {Tabel }}$ & Kesimpulan \\
\hline$X-Y$ & 20 & 0,8938 & 0,444 & Signifikan \\
\hline
\end{tabular}

Sumber: Peneliti

Di peroleh $\mathrm{r}_{\text {hitung }} 0,8938$ dengan $\mathrm{N}=$ 20 untuk $\alpha=0,05$, maka $r_{\text {tabel }} \quad 0,3610$; sehingga

$r_{\text {hitung }} 0,8938>r_{\text {tabel }} 0,444$. Berdasarkan

perhitungan regresi linear sederhana dapat disimpulkan bahwa ada pengaruh kelompok kontrol terhadap kecepatan tendangan depan pada pesilat PSHT Cabang Lampung Barat. 
Jurnal Kejaora: Jurnal Kesehatan Jasmani dan Olah Raga

ISSN: 2541-5042 (Online)

ISSN: 2503-2976 (Print)

Volume 5 Nomor 2, Edisi November 2020

kekuatan otot guna mencapai tujuan tertentu misal memperbaiki kondisi fisik, kesehatan, kekuatan, prestasi dalam cabang olahraga dan sebagainya. Hasil penelitian ini sesuai dengan pendapat Mylsidayu (2015) peningkatan hasil latihan terjadi dalam waktu 2-5 minggu, apabila latihan dilakukan minimal $3 x$ seminggu, dan maksimal $12-14 x$ dalam seminggu. peningkatan hasil pretest ke postest tendangan depan juga terjadi karena beban latihan yang diberikan semakin meningkat frekuensi latihan juga meningkat menjadi $70 \%$.

Menurut Sukirno dan Waluyo (2012) mengatakan bahwa latihan merupakan suatu proses yang sistematis berulang-ulang dengan semakin hari semakin menambah jumlah beban latihan yang diberikan. Peningkatan hasil latihan pada kelompok eksperimen disebabkan adanya proses latihan yang sistematis dan berulang-ulang dan jumlah beban yang diberikan semakin hari semakin bertambah atau meningkat.

Setelah dilakukan latihan selama 5 minggu tanpa perlakuan hasil tendangan kelompok kontrol tertinggi adalah 19 dan yang terendah adalah 16. Hal tersebut dikarenakan calon atlet pada kelompok kontrol tidak diberi perlakuan (latihan menggunakan beban dempel). Meskipun kelompok kontrol tidak diberi perlakuan berupa latihan seperti kelompok eksperimen namun kelompok kontrol juga mengalami peningkatan. Hal ini sesuai dengan pendapat (Mylsidayu 2015) bahwa peningkatan latihan terjadi secara signifikan apabila sekurangkurangnya latihan $3 x$ seminggu dan selama 4 minggu. (Harsono 2010), latihan adalah proses berlatih yang sistematis yang dilakukan secara berulang-ulang yang kian hari semakin terbiasa melakukanya.

Sukadiyanto (2005) mengatakan juga bahwa Latihan adalah suatu proses menyempurnakan kemampuan berolahraga yang berisikan materi, teori, dan praktik menggunakan metode dan aturan sehingga tujuan dari latihan tersebut dapat tercapai tepat pada waktunya. Menurut hasil pengamatan dan observasi yang dilakukan terhadap calon atlet kelompok kontrol pada saat penulis melakukan penelitian, meskipun kelompok kontrol tidak diberi perlakuan

berupa latihan seperti kelompok eksperimen namun kelompok kontrol juga mengalami peningkatan. Peningkatan tersebut terjadi karena kelompok kontrol tidak terkontrol oleh peneliti sehingga sebagian kelompok kontrol ada yang berolahraga lain seperti joging, sepakbola yang otomatis melatih kekuatan, kecepatan kaki dan mungkin kelalaian dari peneliti sehingga kelompok kontrol melihat treatment apa yang diberikan peneliti kepada kelompok eksperimen. Hal inilah yang mempengaruhi peningkatan hasil tendangan depan pada calon atlet kelompok kontrol.

Latihan menggunakan beban dempel modifikasi terhadap kelompok eksperimen selama 5 minggu, sedangkan kelompok kontrol tidak diberi perlakuan. Hasil dari perlakuan calon atlet pada kelompok eksperimen yang mengikuti latihan menggunakan beban ternyata sangat baik. Calon atlet yang tidak diberikan perlakuan (kelompok kontrol) ternyata tidak membawa peningkatan kecepatan tendangan depan yang signifikan. Peningkatan hasil latihan pada kelompok eksperimen disebabkan adanya proses latihan yang sistematis dan berulang-ulang dan jumlah beban yang diberikan semakin hari semakin bertambah dilakukan dari yang mudah ke yang sukar, ringan ke yang berat, dan dari kuantitas ke kualitas (Mylsidayu 2015). Tujuan latihan secara umum adalah membantu para pembina agar dapat menerapkan dan memiliki kemampuan konseptual serta keterampilan dalam membantu mengungkapkan potensi atlet mencapai puncak prestasi. Sedangkan sasaran latihan adalah untuk meningkatkan kemampuan dan kesiapan dalam mencapai puncak prestasi.

Sukirno (2012) mengatakan bahwa latihan merupaka suatu proses yang sistematis berulang-ulang dengan semakin hari semakin menambah jumlah beban latihan yang diberikan.

Menurut Bompa (2014) mengatakan bahwa latihan adalah aktivitas olahraga yang sistematis dalam jangka waktu yang panjang yang ditingkatkan secara progresif dan individual yang ditunjukan pada pembentukan fungsi fisiologis dan psikologis manusia untuk memenuhi tuntunan tugas. Suatu latihan harus dapat menghasilkan peningkatan 
Jurnal Kejaora: Jurnal Kesehatan Jasmani dan Olah Raga

ISSN: 2541-5042 (Online)

ISSN: 2503-2976 (Print)

Volume 5 Nomor 2, Edisi November 2020

keterampilan, kekuatan dan sistem energi yang digunakan pada cabang olahraga yang bersangkutan dalam rangka mencapai tingkat penampilan yang maksimal.

\section{KESIMPULAN}

Berdasarkan hasil penelitian dan pembahasan, dapat disimpulkan bahwa ada perbedaan pengaruh hasil tendangan depan pesilat (posttest) menggunakan beban dempel pesilat di Padepokan PSHT Cabang Lampung Barat.

\section{DAFTAR PUSTAKA}

Arikunto. (2010). Prosedur Penelitian Suatu Pendekatan Praktik. Jakarta: Rineka Cipta.

Bahagia. (2010). Media Dan Pembelajaran Penjas. Bandung: FPOK UPI.

Bompa. (2014). Penelitian Eksperimen. Surabaya: Dua Putra Utama.

Harsono. (2010). Coaching dan Aspek-Aspek Dalam Coaching. Jakarta: PT Dirjen Dikti P2LPT.

Harsono. (2012). Aspek-aspek Dalam Pelatihan. Jakarta: PT Dirjen Dikti P2LPT.

Husin, S. (2010). Pengaruh Pelatihan Plyometric Lompat Bangku Terhadap Daya Ledak Otot Tungkai Bawah. Surabaya: Universitas Negeri Surabaya.

Irianto, D. P. (2011). Dasar Kepelatihan. Yogyakarta: FIK UNY.

Koesopangat, I. (2012). Pendekatan Keterampilan Taktis Dalam Pembelajaran Pencak Silat. Jakarta: Rektorat Jenderal Olahraga.

Lingga, D. P. (2017). Pencak Silat. Bandung: Cipta Bandung.

Lubis, J. (2010). Dasar-dasar Pencak Silat. Jakarta: Kharisma Putra Utama Offset.

Lubis, W. (2014). Dasar-dasar Pencak Silat. Kharisma Putra Utama Offset: Jakarta.

Maryono. (2012). Keyakinan dan Kekuatan. Banten: Yayasan Pustaka Obor Indonesia.

Milsydayu. (2015). Psikologi Olahraga Bandung. Bandung: PT. Remaja Rosdakarya. 